\title{
Applications of Computer Communications in Education: An Overview
}

\author{
Betty Collis, University of Twente
}

\begin{abstract}
ABSTRA Applications of computer communications can be used in many ways in education. In this article an overview is given of a number computer communications applications in learning-related activities. Particular attention is given to a new type of system called a course-support environment. In this type of system a database is integrated with Web-based tools and applications, and used to generate a course-support environment accessed via a standard Web browser. Some examples are given. The article moves on to an overview of various issues confronting the acceptance of computer-communication systems in educational settings, and indicates some of the ways in which computer communications engineers will have to deal with those issues.
\end{abstract}

7 he term tele-learning is used by different persons in different ways. Some take it as synonymous with distance education, and thus assume that it means a course situation in which the instructor is at one location and the learners at another, with their only form of communication via technology. In some situations this form is most typically one-way video with some sort of backward channel for questions. In other situations this contact is predominantly asynchronous, via e-mail, computer conferencing, or a Web environment. Others use the term tele-learning more metaphorically, to capture the sense of being part of a global community of learners or a virtual learning community. In this article the use of the term is more precise. Tele-learning is used here as a general term to refer to the use of computer communications for learning-related purposes [1]. Thus, a team of students working collaboratively on a project in a single location could make productive use of a groupware or shared-workspace application, and thus be participating in a form of computer-communications-supported learning, without physical distance or even temporal distance being involved.

\section{Categories of Computer Communications for LEARNING-RELATED PURPOSES}

What are examples of types of computer communications being used for learning-related purposes? A categorization could occur in many ways and with many overlaps. Table 1 gives one nonexhaustive inventory.

The examples in Table 1 identify types of computer communications applications grouped around five main categories relating to the purpose of the application. This approach emphasizes the functionalities of the computer communications applications: what the user can do with them. These functionalities partially determine the utility of the applications: the extent to which the functionalities match the desires of the users for the intended tasks. Certain technical developments are enhancing both the usability and utility of computer communications applications for educational purposes. Mobile code and applets, new developments in handling asynchronous video, and databasegenerated Web environments are three main examples.

\section{Mobile COde AND APPLETS}

While convergence on the IP (Internet) and HTTP (hypertext transfer) protocols which underlie Web environments has been a powerful breakthrough in terms of stimulating the use of computer communications applications in mainstream education, utility has been substantially heightened through the introduction of browsers which support mobile code, programs that can be transmitted across a network and executed on the receiving computer. Most important for educational situations is the fact that such mobile code now allows interactivity and, increasingly, more and more of the benefits of traditional educational software within a distributed, platform-independent situation. The development of programming languages to produce such mobile code is a major breakthrough in the educational potential of computer communications. Java, developed by Sun Microsystems, is perhaps the best-known mobile code. Units of Java mobile code are called applets. Java-enabled browsers incorporate the Java runtime system which provides functionality to the applets. Such applets in an educational context allow, among other things, instructional animations, interactive quiz and tutorial systems, and simulations, and support the manipulation of multimedia (e.g., [3], and also the Gamelan Web site, ${ }^{1}$ the official directory for educationally oriented Java applets.) Hundreds of applets are available for downloading at this site; for example, supporting engineering education alone there are more than 100 registered, with topics such as the demonstration of computational fluid dynamics, the provision of an environment for the building and testing of digital circuits, the investigation of the mechanical design of various structures, and simulations of various sorts such as Reed and Afjeh's gas turbine.

\section{AsynCHRONOUS AND STREAMING VIDEO}

In addition to mobile code, another important technical development affecting the future of computer communications in education relates to the compression, storage on a video serv$\mathrm{er}$, and streaming of audio and video over networks, particularly video on demand within Web sites where the video and audio material has been naturally captured during a presentation or discussion and can be reused when desired as hyperlinked segments. These developments not only allow the synchronous reception of a presentation such as a lecture via

\footnotetext{
1 Gamelan: the official directory for Java (Web document; see http://www.gamelan.com).
} 


\begin{tabular}{|c|c|}
\hline Major purpose & Applications of computer communications \\
\hline $\begin{array}{l}\text { 1. Publication, information } \\
\text { dissemination }\end{array}$ & $\begin{array}{l}\text { HTML editors; Web sites and the browsers to access them; Web sites associated with database } \\
\text { environments; software to facilitate file transfer and document attachments to e-mail, tools for } \\
\text { cross-application format retention (ie., pdf) }\end{array}$ \\
\hline 2. Communication & $\begin{array}{l}\text { E-mail systems; computer conferencing tools, including Web boards and other forms of Web-based } \\
\text { conferencing; Web sites offering communication options including mailto: for the direct sending of } \\
\text { e-mail and common gateway interface (CGI) forms for structured communication; software for Internet } \\
\text { telephony; software environments for audio-video desktop conferencing, for voice-e-mail, for creating } \\
\text { video attachments for e-mail; software systems for text-based chat }\end{array}$ \\
\hline 3. Collaboration & $\begin{array}{l}\text { Groupware, which includes application-sharing software, shared workspaces, Web-based shared } \\
\text { workspaces, Web-based application sharing, workflow tools; computer conferencing suites; Web sites } \\
\text { designed for collaboration support; tools to allow collaborative writing on documents that are then } \\
\text { commonly available to a group. }\end{array}$ \\
\hline $\begin{array}{l}\text { 4. Information and } \\
\text { resource handling }\end{array}$ & $\begin{array}{l}\text { Web-based search engines; distributed database systems (Web and proprietary); Web sites designed } \\
\text { for information organization, access, and sometimes creation; tools to retrieve and display distributed } \\
\text { multimedia resources stored as digitized audio and video (including streaming audio and video) }\end{array}$ \\
\hline $\begin{array}{l}\text { 5. Specific for teaching and } \\
\text { learning purposes }\end{array}$ & $\begin{array}{l}\text { Applets for interactive software (such as tutorials, quizzes, simulations) accessible via Web sites; testing } \\
\text { systems accessible via Web sites; video-capture tools for lecture or presentation capture; video- } \\
\text { conferencing (point-to-point and multicasting) for lecture participation; video on demand and streaming } \\
\text { video for lecture capture and re-use; Web-based course-support environments; database-generated } \\
\text { course-support systems, integrating many or all of the applications in this table along with management } \\
\text { tools }\end{array}$ \\
\hline
\end{tabular}

Table 1. Applications of computer communications; general categories in terms of learning-related purposes [2].

the Internet, but, more important, allow its review on demand, in either linear form or interactively, with learner choice of location within the linear sequence at which to access a particular segment of the captured video. Tools to also allow synchronized presentation of the screen display material being used by the instructor or presentor are further increasing the learning value and flexibility of the captured video material. For examples, see exploratory studies related to the use of asynchronous video/audio in Web environments for learning purposes from the Universitat Freiburg [4] and from Old Dominion University in Virginia [5].

\section{DATABASE-GENERATEd COURSE-SUPPORT ENVIRONMENTS}

A third important technical development relating to computer communications in education involves the linking of a Webcompliant (i.e., accessible via a Web browser) user interface and Web-compliant tools and applets with an underlying database. Such systems support managed learning operations, presenting a tailored Web environment to the individual user based on the privileges associated with the user and information about the user maintained in the database (e.g., see the system used at the University of Twente via http://teletop.edte. utwente.nl [6]).

In its simplest form, a course-support environment is a Web site that accompanies an existing course and contains some information about the course. More complex coursesupport environments offer some or many of the forms of support shown in Table 2. The purpose of such sites is to increase the efficiency of aspects of course participation, enrich some aspects of course participation, and/or make some aspects of course participation more flexible to better meet the needs of individual students [2].

With course-support environments, no one course needs to include all of the options shown in Table 2. The instructor selects those options that relate to his or her own course and its situation. Course-support environments can be simple or complex pedagogically as well as technically. When a coursesupport site facilitates a substantially different learning experience from the course taught without the site, we say that pedagogical reengineering has occurred. Course-support sites can be created and maintained by the individual instructor, but increasingly such sites are maintained as part of an integrated system serving an entire department or faculty.

Many examples of integrated Web-based course-support environments can be mentioned in addition to the example at the University of Twente. A few examples from European universities follow. At Janus Pannonius University in Hungary, an integrated course-support site allows students convenient access to the MAPLE algebraic computing system and a variety of other study aids as well as pretests, lecture notes, mailboxes for communication, and other forms of interactive quizzes. At Robert Gordon University in the United Kingdom, the Web-based support site for a course in research methods brings together tools to use in research activities, links to external sites which provide databases and examples of survey research results, links to tutorials and additional study materials, search tools, and locally created study materials, which together form a "Web Resource Centre for Acquiring and Accessing Open Learning Materials on Research Methods (ReMOTE)." At the University of Barcelona a number of communication tools, such as a "Private area" and a "Public area," are integrated within a Web site to support an environmental education course. At the Technical University of Braunschweig, Germany, a course in advanced computer networks makes extensive use of an integrated Web-based support environment. At the University of Malaga, Spain, the problem of how to test students in courses requiring the use of a computer for the final test (e.g., computing courses), when there are not enough computers available and students must use computers in different parts of the campus is being solved by an intranet-based secure test system. At Vrije University, Amsterdam, students use Web-based "virtual learning environments" to support team learning, to be informed about course-related issues, to communicate with each other and the instructors, to publish their results, and for evaluation of their assignments.

The above examples focus on computer communications used within the traditional educational setting in order to enrich the learning experiences and make certain aspects of course participation more efficient and flexible. Flexibility can also allow the extension of traditional courses to nontraditional audiences, including those who could be described as dis- 
tance-education students. There are many cases in European, Canadian, and Australian universities where computer communications applications (involving Web-based platforms) allow flexible participation, including at a distance. Many traditional universities as well as established distance delivery universities now make use of computer communications applications and systems to serve students at a physical distance from the home university.

This overview has only begun to indicate the extent of computer communications use in education, and has not even mentioned the growing use in training situations. ${ }^{2}$ The point is clear: the educational sector is a major market for computer communications applications and services. Thus, the requirements of the educational market will be important for an

${ }^{2}$ See, for example, the Teleman Site, at http://www.teleman.org, for hundreds of further examples.

\begin{tabular}{|c|c|}
\hline Course aspect & iment, and/or flexibility \\
\hline $\begin{array}{l}\text { 1. General course } \\
\text { organization }\end{array}$ & $\begin{array}{l}\text { "Newsflash" areas on the Web site present announcements, changes, updates } \\
\text { Administrative information (names of students, e-mail addresses, scores to date, etc) are available through the } \\
\text { Web site } \\
\text { Faculty bureau maintains channels of personal contact and availability, printed material still available on courses, } \\
\text { timetable, etc, e-mail and the Web used for student contact, updates in information, signups for elective } \\
\text { courses, etc. } \\
\text { The instructor still provides a course outline but also has it on the Web; all updates and announcements are on } \\
\text { the Web or via e-mail } \\
\text { The course-support site is integrated with other Web sites with faculty-wide information }\end{array}$ \\
\hline 2. Communication & $\begin{array}{l}\text { Convenient communication through an e-mail center in the Web sites, where not only can individuals be } \\
\text { reached but also groups within the course (via aliases). Group members can have their own private } \\
\text { communication areas within shared workspaces } \\
\text { The opportunity for guided reflective discussions via a Web board (a form of computer conferencing within a } \\
\text { Web site) } \\
\text { Tools for scheduling and carrying out real-time communication at a distance including chat, Internet telephony, } \\
\text { desktop meeting tools (such as NetMeeting) }\end{array}$ \\
\hline $\begin{array}{l}\text { 3. Lectures, instructor } \\
\text { presentations }\end{array}$ & $\begin{array}{l}\text { Notes available before a lecture via the site } \\
\text { Highlights of lectures are captured as digitized video, made available as streaming video on the Web, } \\
\text { synchronized with notes, for students not physically present } \\
\text { Follow-up reflections or questions can be posted and responded to via various Web-based forms and } \\
\text { communication tools at the course site }\end{array}$ \\
\hline $\begin{array}{l}\text { 4. Self-study and } \\
\text { practice }\end{array}$ & $\begin{array}{l}\text { Expand existing study materials by adding interactive tools (such as applets) for self-study via the Web } \\
\text { Expand and update study materials by using links to additional resources via the Web } \\
\text { Provide support for exercises and small assignments, by having them submitted via the Web site and by being } \\
\text { able to offer: } \\
\text { - direct (automatic) feedback (for exercises with a predetermined correct answer) } \\
\text { - making a model answer available via the Web after the student has submitted his work } \\
\text { - by the students to each other (possible when student responses are available via the Web site) }\end{array}$ \\
\hline 5. Group based projects & $\begin{array}{l}\text { Offer tools to support group activities such as a shared workspace } \\
\text { Require continual posting on the Web site of work relating to the ongoing progress of project work, such as } \\
\text { design decisions, task allocation agreements, draft versions; use the Web site for students to give each other } \\
\text { feedback on work in progress and for instructor comments } \\
\text { Link final products to the Web site and include student reflection on each other's work as part of the course } \\
\text { requirements }\end{array}$ \\
\hline 6. Evaluation & $\begin{array}{l}\text { Present some forms of evaluation such as reflective comments via the Web, where questions are posted at a } \\
\text { certain time and responses must be submitted within a specified time limit } \\
\text { Provide password-protected test sessions, with automatic feedback when appropriate to the form of the test } \\
\text { question }\end{array}$ \\
\hline
\end{tabular}

Table 2. Examples of support types in Web-based course-support environments. 
increasing number of computer communications engineers in the years to come. What should computer communications engineers particularly know about this sector and its problems and requirements?

\section{ISSUES AfFeCtING THE ADOPTION AND UTILIZATION OF COMPUTER COMMUNICATIONS SYSTEMS AND APPLICATIONS IN THE EDUCATIONAL SECTOR}

Issues relate to sociocultural, human, organizational, and technical aspects. Some examples follow.

\section{Staff Engagement AND SUPPort}

As soon as the use of computer communications moves from the pioneer/special project phase to the institutionalization phase in an educational setting, a new set of critical issues arises. These issues have to do with convincing new users that change via the use of computer communications is of advantage to them personally, and that the time and effort it will take them to handle the change will not be unduly large. Hammond and Karran in the United Kingdom identify "lessons learned" about staff engagement, and indicate that "the crucial ingredient is the participation of staff at all levels in proposed development" [7, p. 232]. Such full-scale participation is hard to secure unless staff are sufficiently stimulated, usually by the central administration. But top-down change is notoriously difficult to carry out in university contexts, so the balance between sufficient administrative stimulation and too much for academic acceptance is delicate. Staff engagement, even when willingly occurring, takes time that many faculty feel to be excessive given their research-related responsibilities [8]. Also, many academics feel strongly that the ways they have always taught are in fact the appropriate ways to teach their own discipline; change for abstract reasons such as the future of the university does not weigh heavily enough to convince them to teach in what they feel will be an "inappropriate way" for their course and habits. Many different initiatives are occurring in traditional universities to deal with these issues involving staff engagement, most typically through centrally situated teaching and learning centers. One of many examples is that of the University of Genoa, where a Web environment is being built to assist instructors in making use of computer communications applications in their teaching [9]. These centers, however, generally only deal with those who volunteer for their services, thus missing the hardcore resistance confronted when an entire faculty must change. Also, such centers typically do not work in an integrated way with the computer services units; nor do their staffs, as persons trained in education, tend to be people well informed technically with respect to network issues. Thus, the computer communications engineer must learn to communicate appropriately with those from nontechnical backgrounds who may be dubious about the use of any form of computer communications.

\section{ISSUES RELATED to TECHNICAL INVESTMENTS}

The majority of universities throughout the world have some sort of network infrastructure, and some sort of central service bureau for this infrastructure. Increasingly, in universities not in highly disadvantaged settings, most faculty members have some way to access the university network and also the Internet. There is usually some sort of computer laboratory for students, but the adequacy, both quantitive and qualitative, of access to such facilities differs widely among and within universities. It is increasingly likely that students have some sort of Internet access and their own e-mail accounts, although again this varies widely, from low percentages to 100 percent, both between and within universities. Thus, the majority of traditional universities are making investments in computer communications services and network connectivity. Schools and training centers are slower to move to networked status, and thus slower to make use of computer communications. However, regional and national plans are either in place or under development in many countries to provide Internet access to all schools or at least a selection of schools. ${ }^{3}$ However, as soon as the institution decides to become more proactive regarding computer communications use, serious and costly efforts must be made and continually upgraded.

Also, issues with respect to the design, construction, and maintenance of the Web-based support environments becoming widespread in traditional universities are demanding considerable attention. Should a university build its own system, or license a system maintained by others? (See [10] for an analysis). Should central decisions be made regarding licensing of, for example, groupware or workflow or intranet environments, or should the individual department or unit choose its own solution? What sort of access provisions should be offered to staff and students, on campus and off? Should partnerships be formed with data communication service providers or, as is increasingly happening in Europe, with regional cable companies? What quality of service level is adequate for different types of schools and educational settings? What are the bandwidth requirements? And, within the next few years, how can mobile computer communications (wireless or nomadic connectivity) be integrated into the infrastructure support in an organization?

Increasingly, institutions such as schools need to make informed decisions about network options, and about the migration of their previously local systems to systems integrated in intranet or extranet settings or directly connected to the Internet. Finding adequate support for informed decision making is a critical problem for many small institutions in the educational market. The computer communications engineer, often serving as a representative of a telecommunications service, will be called on to communicate with an audience who do not share his or her level of technical understanding, but need informed advice before making decisions about quality and type of service for their institutions.

\section{DESIGNING FOR USABILITY}

A different perspective on the application of computer communications for learning-related purposes relates to the user interface and human-computer interaction aspects. In these aspects it is not only what the user can do with the application that matters, but how he or she can handle the product. What does the user see on the screen? What needs to be done to make the software respond? Aspects such as these relate to the usability of the computer communications application. Nielsen defines main aspects of usability from the software engineering perspective as including [11]:

- Learnability: how hard or easy it is for the user to figure out how to handle the software so that the desired utilities become available

- Retention: how easy it is, after some time away from the software, to be able to handle it

- Consistency: how careful the designer of the software was to maintain visual, metaphorical, textual, and usage patterns wherever one is in a software environment

${ }^{3}$ For the European case see the European School Network site, sponsored by the European Union, at http://www.eun.org 
- Error handling: how helpful the software is when an action occurs that the user does not expect

- Subjective satisfaction: how pleasing it is to manipulate the software

To this list can be added aspects that have been extensively studied from other disciplines. Spohrer [12], from the human-computer interaction perspective, notes the importance of cognitive and social fit in terms of potential usability and dissemination. From the educational software perspective, there is much research to indicate the importance of factors such as readability, cultural appropriateness, and pedagogical, curricular, and instructional fit relative to a specific learning context. With regard to the hyperlinked environments accessed by Web browsers, other aspects are also critical to the usability of computer communications, particularly:

- Navigation support: how easy is it for the user to find his or her way to what is wanted and back again

- Overview support: how easily the user can develop an accurate mental model of the site and the functionalities offered

Both utility and usability are critical to eventual use in practice, or what Schakel calls the system acceptability of a product [13]. Utility is a necessary but insufficient aspect; without adequate usability, even a computer communications application with high potential utility will not be likely to be used. Moonen calls this the difference between internal and external acceptability [14]: in theory, the product may have desirable utility. Its internal acceptability is high. However, in practice the intended user is not attracted to using the product: its external acceptability is low. Computer communications engineers must also have some understanding about the subjective aspects of user interface design, the psychology of the potential user, and the factors that influence the social climate in an institution with respect to innovations in teaching and learning, with or without computer communications.

\section{CONCLUSION AND LOOKING TO THE FUTURE}

The educational sector is becoming a major area for the application of computer communications. Although in many ways the needs of this sector are similar to those of other sectors, particularly in terms of affordability and reliability, there are differences to which computer communication engineers need to be sensitive. User interface and usability issues are extremely important. In education, the instructor will remain a critical decision maker in terms of if and how computer communications are used in a course. If the instructor is uncomfortable with the use of computer communications, he/she is not likely to persist in this use. Thus, user concerns and characteristics need to be carefully considered.

In terms of the needs of a critical mass of users, quality of service indicators relating to high-bandwidth applications such as videoconferencing are less important than indicators relating to secure connections to the database systems which are rapidly becoming integrated with Web-based course-support environments. Web environments supporting asynchronous access are and will continue to be in much broader use in education than situations involving real-time communication.

Access issues are particular barriers. The majority of classrooms and lecture halls still do not have fixed network connection points, thus limiting the natural use of Web-based resources during a presentation for demonstration or as examples. Mobile connectivity is likely to make a major difference in the use of Web-based resources in actual presentation settings. Also, the need to quickly log into a Web-based coursesupport site, upload and download files, check for course updates, and handle some brief communication is escalating now that such sites are increasingly in use in higher education. Again, mobile computing will make a substantial difference in facilitating this access. However, many technical issues must be solved before such mobile access can be as straightforward for the user as mobile voice communications has become. Particular issues for the engineer relate to protocols and data formats for transmitting to mobile devices, markup languages appropriate for low-bandwidth wireless environments, capability negotiation when signals must move through different network situations, document filtering, and quality of service selection. Middleware support will be critical in ensuring the effective fit of protocols and data formats, but to do so must consider the requirements of evolving applications, the limitations of mobile devices, and the capabilities of wireless network technologies.

The educational sector is large; as computer communications become firmly established within this sector, a trend that is well underway, the engineer will need to become familiar with its specific characteristics and the factors within it that most influence the success or failure of computer communications use.

\section{REFERENCES}

[1] B. A. Collis, Tele-Learning in a Digital World: The Future of Distance Learning, International Thomson, 1996.

[2] B. A. Collis, "Teleware: Instrumentation for tele-learning," Inaugural address, Chair in Tele-Learning, Univ. of Twente, Enschede, The Netherlands, Oct. 1, 1998.

[3] J. A. Reed and A. A. Afjeh, "Developing interactive educational engineering software for the World Wide Web with Java," Comp. \& Educ., vol. 30 , no. 3/4, 1998, pp. 183-94.

[4] C. Bacher and R. Muller, "Generalized replay of multi-streamed authored documents," Proc. ED-MEDIA/Ed-Telecom '98, vol. 1, Freiburg, Germany, June, 1998, pp. 87-92.

[5] K. Maly et al., "Automated content synthesis for interactive remote instruction," Proc. ED-MEDIA/Ed-Telecom '98, vol. 2, Freiburg, Germany, June, 1998, pp. 896-901.

[6] B. A. Collis and W. F. De Boer, "Rapid prototyping as a faculty-wide activity: An innovative approach to the redesign of courses and instructional methods at the University of Twente," Educ. Media Int'l., vol. 35 , no. 2, 1998, pp. 117-21.

[7] R. Hammond and T. Karran, "Implementing a computer mediated learning environment: People, problems and practicalities," Universities in a digital age: Transformation, innovation, and tradition, Euro. Distance Educ. Network, 1998, pp. 230-34.

[8] N. E. Seminoff and S. B. Wepner, "What should we know about technology-based projects for tenure and promotion?" J. Res. Comp. in Educ., vol. 30, no. 1, 1997, pp. 67-82

[9] J. L. Marzo et al., "Support units for university teaching based on Web," Proc. ED-MEDIA/Ed-Telecom '98, vol. 1, Freiburg, Germany, June, 1998, pp. 913-18.

[10] T. Dietinger, H. Maurer, and M. Pivec, "Multimedia learning environment: Combining easier courseware production and new learning methods," Proc. Tele-teaching '98: Distance learning, training and education, Part III, Austrian Comp. Soc., Aug. 1998, pp. 39-49.

[11] J. Nielsen, Usability Engineering, Academic Press, 1994.

[12] J. Spohrer, "ATG education research: The authoring tools thread," SIGCHI Bulletin, vol. 30, no. 2, 1998, pp. 124-33.

[13] B. Schakel, "Usability-context, framework, definition, design and evaluation," B. Schakel and S. Richardson, Eds., Human Factors for Information Usability, Cambridge Univ. Press, 1990, pp. 21-37.

[14] J. C. M. M. Moonen, "The design and prototyping of digital learning material: Some new perspectives," J. van den Akker, N. Nieveen, and T. Plomp, Eds., Design Methodology and Development Research in Education and Training, Kluwer, 1999.

\section{BIOGRAPHY}

BETrY COLLIs (collis@edte.utwente.nl) is professor of tele-learning at the University of Twente, The Netherlands, and also senior researcher in advanced learn ing technologies, at the interdisciplinary research institute Centre for Telematics and Information Technology (CIT) at the same university. Her research areas include the design of systems for Web-based course support and applications of networks and computer communications in higher education, particularly video on demand, and more recently, wireless computing. For more information see http://www.edte.utwente.nl/user/ism/Collis/home.htm. 